\title{
Coronal Mentoplasty: Complementary Technique in Orthognathic Surgery: Cases Report
}

\author{
Francisco Yévenes ${ }^{1 *}$, Gastón Salas ${ }^{1}$, Jorge Lolas ${ }^{1}$, Emilio Moreno ${ }^{1}$ and Pedro Solé2 \\ ${ }^{1}$ Resident of Oral and Maxillofacial Surgery Program, Universidad de los Andes, Santiago, Chile \\ ${ }^{2}$ OMFS, Department of Oral and Maxillofacial Surgery, Universidad de los Andes, Santiago, Chile
}

*Corresponding author: Francisco Yévenes Souper, Resident of Oral and Maxillofacial Surgery Program, Universidad de los Andes, Avenida Monseñor Álvaro del Portillo 12455. Las Condes, Región Metropolitana de Santiago, Chile, Tel: +56997135940

\begin{abstract}
Both vertical and horizontal maxillo-mandibular discrepancies lead to poor positioning of the tissues, causing alterations in functionality and aesthetics, which today are corrected with increasingly specific procedures. Mentoplasty allows modifying the anatomy of the chin in the 3 senses of space.

There are cases in which a receding Mentoplasty or Genioplasty cannot be performed, either due to very prominent chins, which cannot be raised to the chin because there are no vertical alterations causing a decrease in the airway or for other contraindications, being the Coronal Genioplasty a recommended technique.

The Coronal Genioplasty technique has specific indications, which seeks to achieve a predictable, stable result over time and low risk, achieving results by itself or as a complementary procedure.

The purpose of this article is to show the indication for coronal genioplasty in relation to two clinical cases.
\end{abstract}

\section{Keywords}

Osteotomy, Genioplasty, Mentoplasty, Orthognathic surgery

\section{Introduction}

The harmony and facial aesthetics are the result of an adequate proportion between the thirds facial, where the concern for these parameters is in increasing demand. The maxillo-mandibular discrepancies both vertical and horizontal lead to a bad positioning of the tissues, causing alterations in the functionality and aesthetics that today are corrected with increasingly specific procedures.

The lower third of the face must be imperiously included when we talk about the physical appearance, and it is at this point, the chin, added to the associated musculature, play an extremely important role in this balance, harmony and obtaining these parameters $[1,2]$.

Genioplasty is a versatile technique, which can often be complementary to another Osteotomy, which allows modifying the anatomy of the chin in the 3 senses of the space. It was described for the first time in 1942 by Hofer through an approach extraoral, which was modified in 1957 by Trauner and Obwegesser towards an approach intraoral [3]. The recoil of this can also be performed and was described for the first time in a scientific paper by Hinds and Kent in 1969, as well as a vertical reduction (intrusion or impaction) by Reichenbach, et al. in 1965, who described removing a segment or "wedge" $[4,5]$.

This technique presents multiple indications, mainly of function and aesthetics. The main associated complications include mental nerve damage, inadequate consolidation, pseudoarthrosis, asymmetry and irregularities [5], also being reported cases of pulp necrosis in the anterior inferior teeth after fixation of the screws [6].

Genioplasty is the second most common facial osteotomy today [5], with a usually intraoral approach through an incision at the vestibular level to the area of the first premolars, exposing the mental nerve bilaterally [7].

Citation: Yévenes F, Salas G, Lolas J, Moreno E, Solé P (2021) Coronal Mentoplasty: Complementary Technique in Orthognathic Surgery: Cases Report. Res Rep Oral Maxillofac Surg 5:060. doi. org/10.23937/2643-3907/1710060

Accepted: October 11, 2021; Published: October 13, 2021

Copyright: (C) 2021 Yévenes F, et al. This is an open-access article distributed under the terms of the Creative Commons Attribution License, which permits unrestricted use, distribution, and reproduction in any medium, provided the original author and source are credited. 


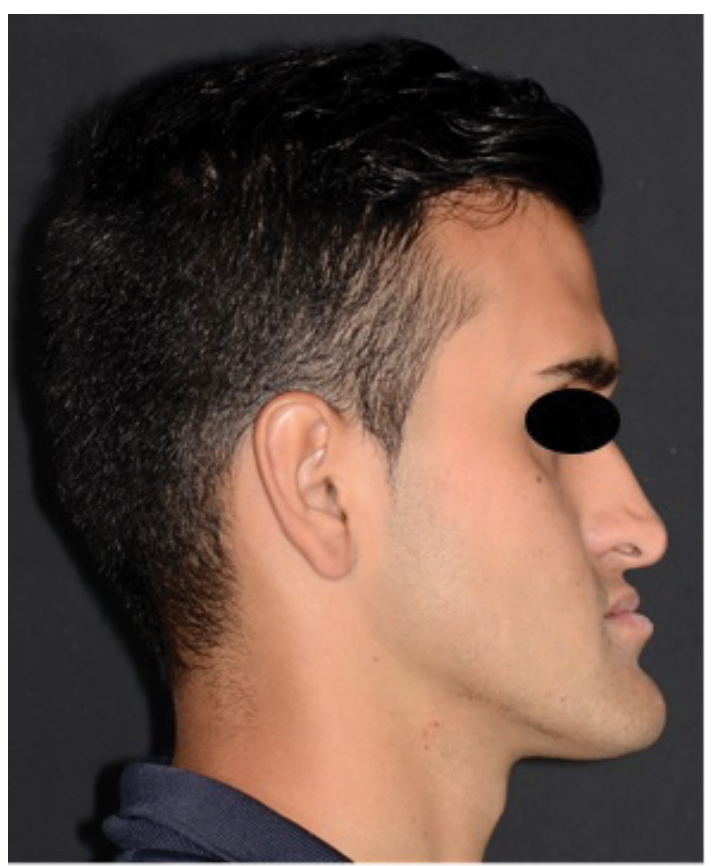

Figure 1: Initial patient 1: Lateral view.

The objective of this article presents the technique of Coronal or vertical Genioplasty, the which consists of the exposure of the chin as a complement in orthognathic surgery, where the vertical cut is made with a reciprocating saw and remove excess tissue bone (up to $6 \mathrm{~mm}$ ). Corresponds to a predictable procedure with good results for the cases that correspond to your indication.

\section{Description of the Technique}

The approach is a lower vestibulotomy between first premolars, with an incision that it passes perpendicular to the level of the mentalis muscle, exposing the subperiosteal plane. The exposure is limited to the symphysis level so as not to remove vascular supply and taking into account consideration of the mental nerves [1]. The midline of the mandible in reference to the dental midline and other facial structures to be determined, subsequently, by using a reciprocating saw and a chisel or osteotome, remove excessive bone tissue (up to $6 \mathrm{~mm}$ ) as planned. The level of the osteotomy should be $5 \mathrm{~mm}$ below the apex of the canine and 6 $\mathrm{mm}$ below the inferior border of the mental nerve $[2,4]$. The fixation can be done by means of plates or screws as the case may be. One time fixation is completed successfully, the surgical site is abundantly irrigated and the closure of the soft tissues, which can be in two layers (muscular followed by mucosa) or just a layer with absorbable suture.

\section{Cases Report}

The first case was a male patient with a skeletal class III associated with a true Macrogenie. This patient was a candidate for Orthognathic Surgery with LeFort I osteotomy to decant the Maxilla, a $6 \mathrm{~mm}$ advance

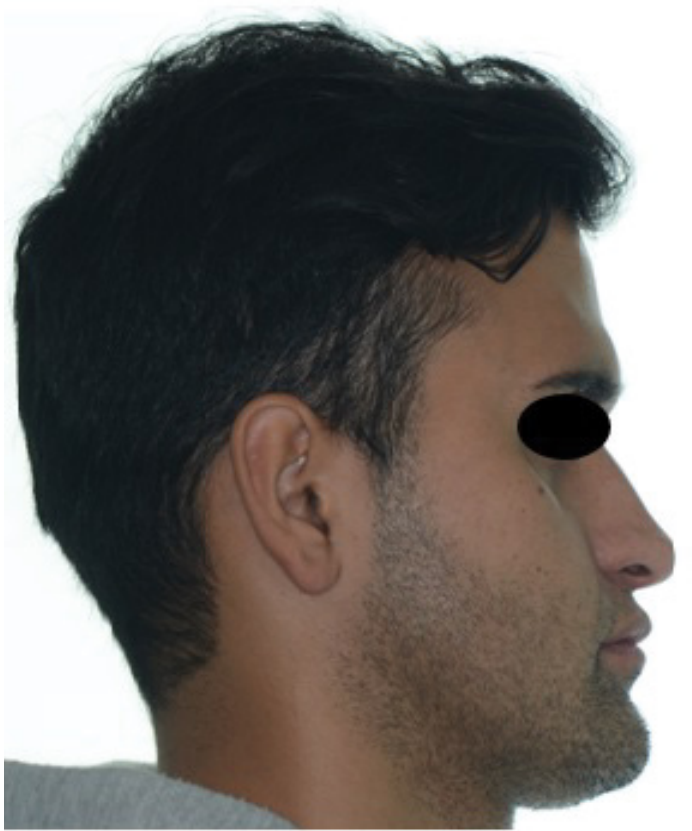

Figure 2: Patient 1: Control photograph 6 months after surgery, side view.
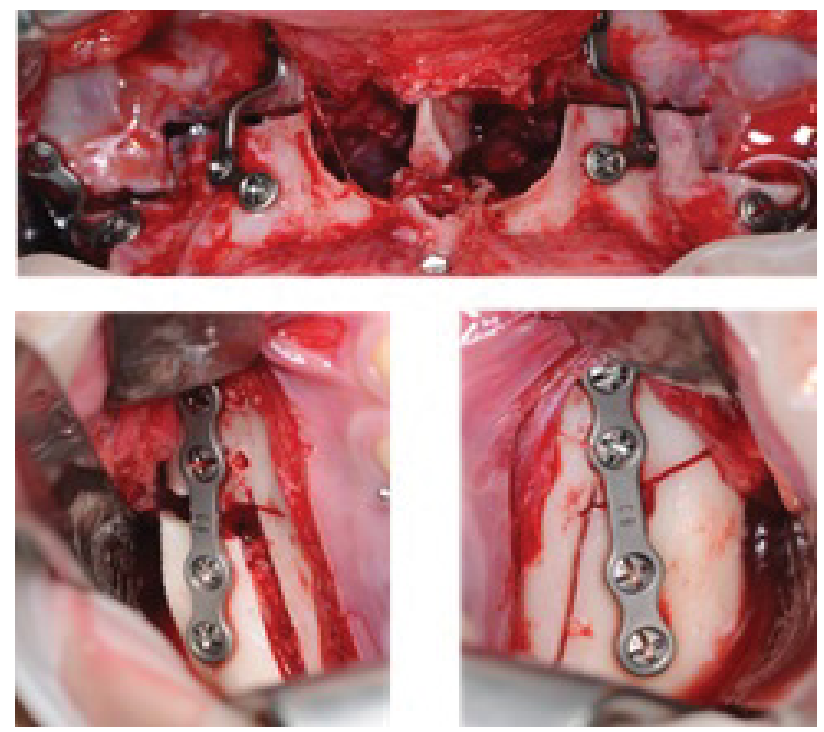

Figure 3: Patient 1: a) Le Fort 1 advance and descent osteotomy; b,c) Osteotomy sagittal branch of mandibular.

on both sides and a $2 \mathrm{~mm}$ descent, a bilateral sagittal osteotomy of the Mandibular Branch with a centering $3.2 \mathrm{~mm}$ to the left and a $0.5 \mathrm{~mm}$ setback, a filing at the level of the back of the septum and a $4 \mathrm{~mm}$ retraction and ascent Coronal Genioplasty (Figure 1, Figure 2, Figure 3, Figure 4 and Figure 5).

The second case was a patient with the same diagnosis as the previous patient (Class III skeletal with a true Macrogenie), where a Le Fort Osteotomy was planned I of advancement and descent Bilateral Mandibular Branch Sagittal Osteotomy and a Coronal Genioplasty.

\section{Discussion}

The projection of the chin and the size of this are 


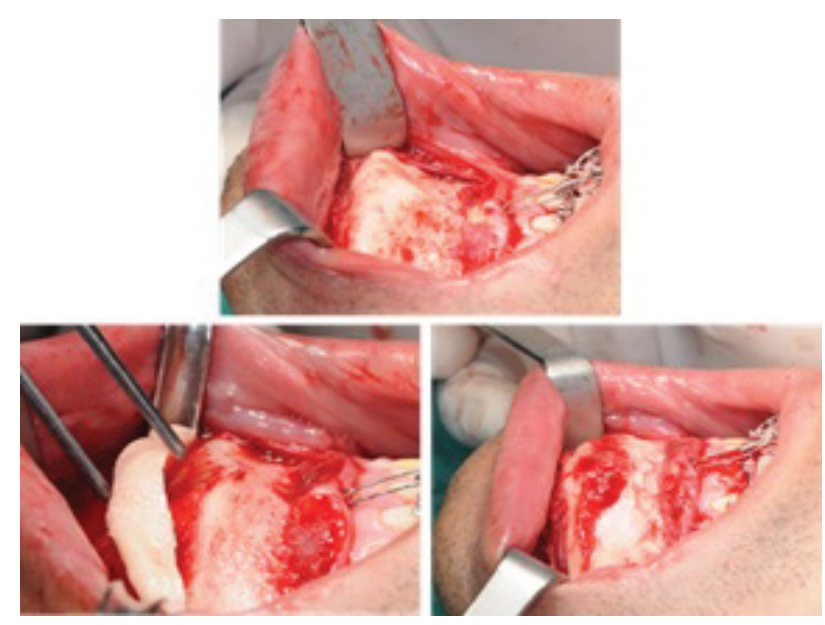

Figure 4: a) Chin decoration showing true hypermentonism; B) Reciprocating saw ostectomy; C) Post ostectomy surgical site and correction Hypermentonism.

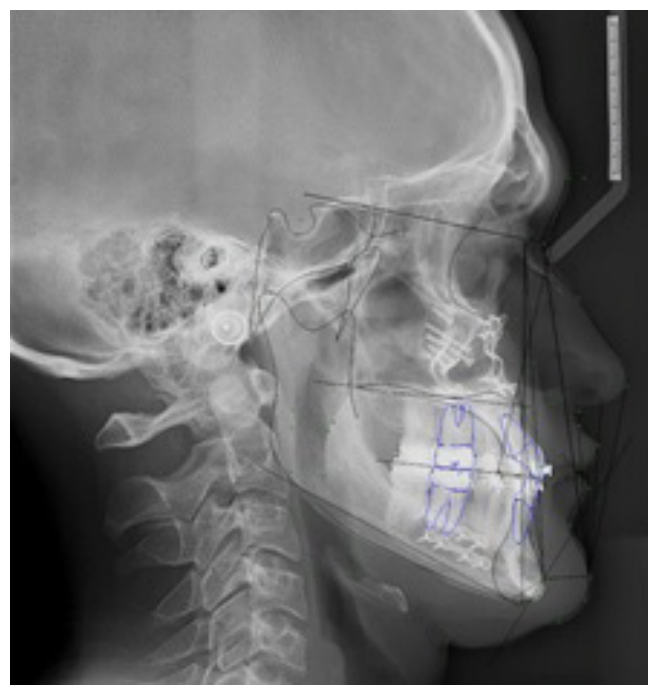

Figure 5: Patient 1: Control cephalometry 6 months after surgery.

fundamental to determine a facial harmony [8]. Both vertical and maxillo-mandibular discrepancies horizontal positions lead to poor positioning of the tissues, causing alterations in functionality and aesthetics, which today are corrected with procedures each time more specific.

More specifically, a disproportion in the lower facial third of the face in all senses of space, will result in an obvious imbalance.

A measurement and analysis of the proportions or facial thirds of both lateral and frontal way. Laterally it decomposes from the Trigion point to the Glabella (upper third); from the Glabela point to Subnasal (middle third) and from Subnasal to Chin at its lowest point (lower third); these must be proportional in 1:1. Without However, Powell and Humphrey defined that due to proportional variations, determined to measure from the Nasion to the Chin, where the measurement of the middle third described above should represent $43 \%$ of the Nasion-Chin distance, while that the lower third should be $57 \%$ of the same previous distance $[1,9]$.
The frontal analysis takes into account the proportions of the facial quintets described in the literature [9], from the inner canthus of the eye to the side; bipupillary plane, width of nasal bridge and chin, midlines, etc. With the same detail, it should be evaluated independently the lower third: lips, mentolabial sulcus, nasolabial angle, chin and menthocervical area. In this analysis, the upper lip relationship (Sub nasal-Stomion) and lower lip (Stomion-Chin) of 1:2 respectively [9].

In addition to this, a meticulous cephalometric analysis must be performed both at the Hard tissues with Burstone-Legan and Holdaway Analysis [10,11], and at the tissue level soft with the González-Ulloa analysis [9].

In these cases, the most used technique corresponds to surgical genioplasty of recoil, however, it is not always possible to use this technique, either for chins very prominent, which cannot be raised chin as compensation due to the fact that there are no alterations at the vertical level of the face and it can decrease the airway by retrusion of the Geni processes of the mandible.

A therapeutic alternative is Coronal Genioplasty to treat these patients previously described under general anesthesia, using a nasal intubation, which allows the Surgeon to evaluate the correct position of the chin in relation to the occlusion and other structures without interference.

In the case of the patients presented, the changes are exposed to the naked eye and aesthetics, but they are also expressed according to facial analyzes, for example, in the patient 1, following the reference of the Burstone and Legan Analysis [12], the distance to level of hard tissues from the Nasion point to the Pogonion, which indicates the prominence of chin in relation to profile went from being $35.3 \mathrm{~mm}$ to $21.5 \mathrm{~mm}$ and in patient 2 a, even a decrease in mandibular length measured from the Gonion to the Pogonion from 81.5 to $76.8 \mathrm{~mm}$ (Figure 6, Figure 7, Figure 8, Figure 9 and Figure 10).

In the case of patient 2, following the BurstoneLegan analysis [12], the distance between Point B and the Pogonion [10], which represents the degree of anterior projection of the chin, decreased from 12.6 to $8 \mathrm{~mm}$, as in patient 1 who decreased this distance from 14.6 to $8.3 \mathrm{~mm}$, which indicates a decrease or elimination of the Macrogenie. It is worth mentioning that in these two cases the Genioplasty is performed as a complementary procedure in the context of an Orthognathic Surgery, which there are values that have to be analyzed in relation to the joint procedure. Genioplasty as a technique is described as an extremely versatile, leading to predictable and long-lasting results improving appearance in aesthetics and functionality by reorienting both bone and muscle, and if well, it is defined as a low-risk procedure, the alteration at the 


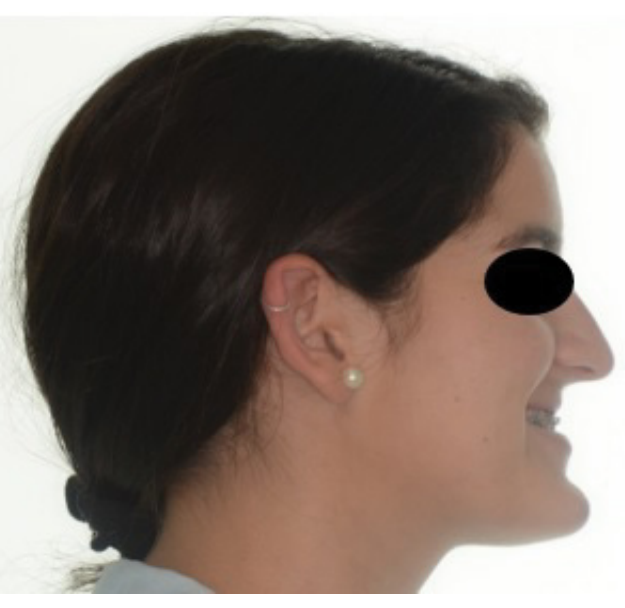

Figure 6: Initial patient 2: Lateral view.

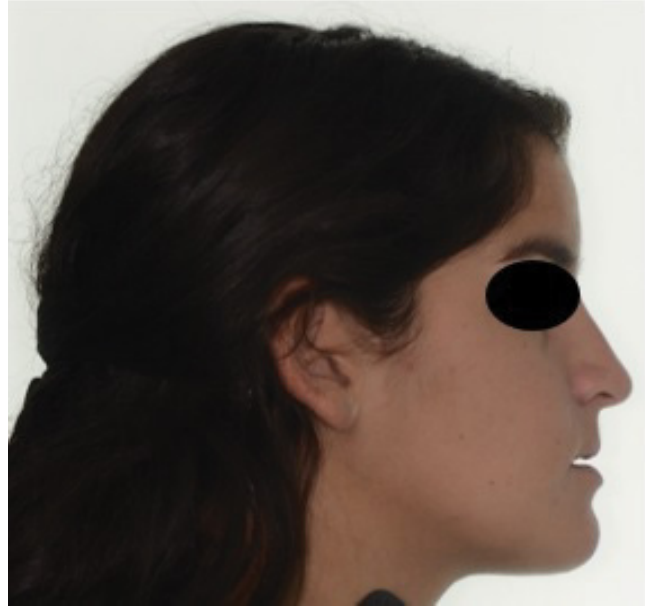

Figure 7: Patient 2: Control photograph 6 months after surgery, Side view.

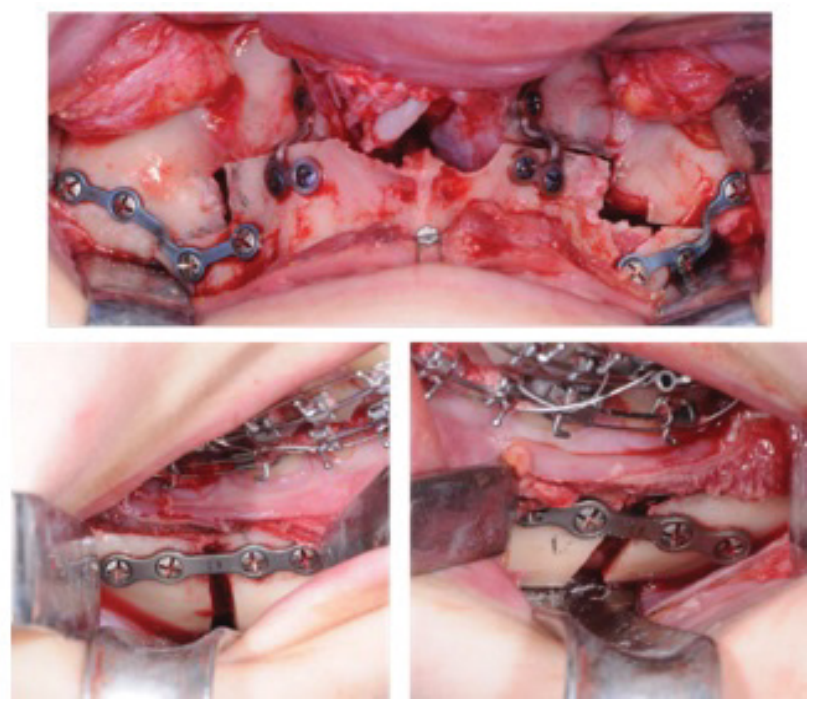

Figure 8: a) Le Fort 1 advance and descent ostectomy; b,c) Sagittal ostectomy of mandibular branch.

neurosensory level is present due to the soft tissues that surround the mental nerves and is so it should always be taken into account to reduce its incidence and in case of introduce yourself, know how to handle it.

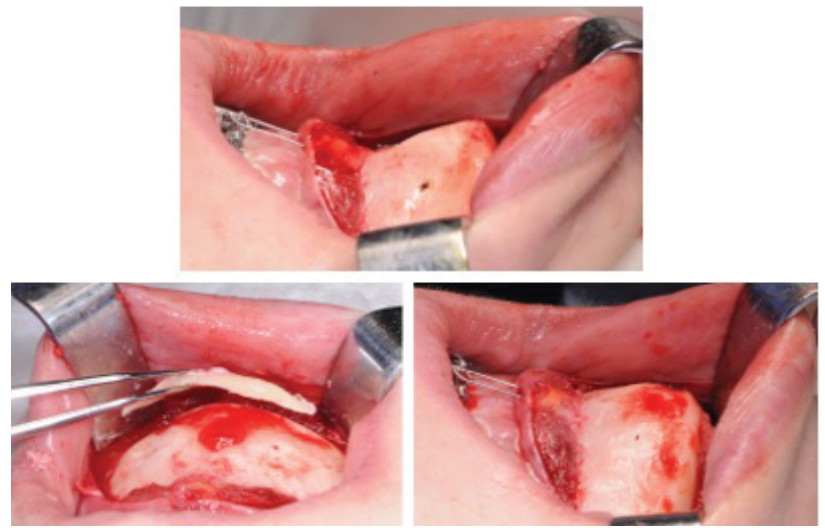

Figure 9: Patient 2: a) Chin decoration where hypermentonism is evidenced true; b) Ostectomy with reciprocating saw; c) Post ostectomy surgical site and Hypermentonism correction.

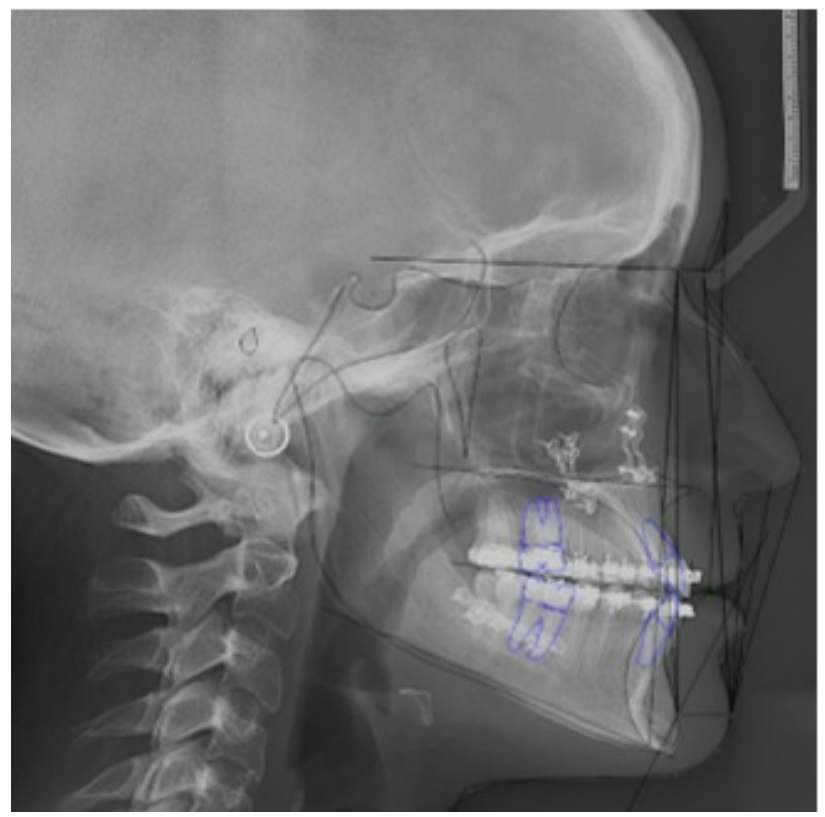

Figure 10: Patient 2: Control cephalometry 6 months after surgery.

This type of Genioplasty in particular is performed as previously presented in patients diagnosed with a skeletal Class III and a True Macrogenie, the which have an indication for receding osteotomies, where with genioplasty as complementary technique, a $4-6 \mathrm{~mm}$ chin setback can be performed without decrease the patient's airway, as it is in a reverse mentoplasty as such.

\section{Conclusion}

Cephalometric analysis of the facial thirds is extremely important to choose and plan the appropriate treatment for each case, so it is imperative to carry out a detailed analysis and have the different therapeutic alternatives for each patient. The Coronal Genioplasty technique has specific indications, which seeks achieve a predictable result, stable over time and low risk, achieving results By itself or as a complementary procedure. 


\section{Financial Disclosure Statement}

The authors have nothing to disclose. No funding was received for this article.

\section{References}

1. Ward JL, Garri JI, Wolfe SA (2007) The Osseous Genioplasty. Clinics in Plastic Surgery 34: 485-500.

2. Colmenero C, Prieto J, Serrano F, Rosón (2012) Mentoplastia: cirugía estética del mentón aislada o en combinación con cirugía ortognática. Gaceta Dental.

3. Moragas SM, Oth O, Büttner M, Mommaerts MY (2015) A systematic review on soft-to-hard tissue ratios in orthognathic surgery part II: chin procedures. Journal of Cranio-Maxillo-Facial Surgery 43: 1530-1540.

4. Chen T, Khadka A, Hsu Y, Hu J, Wang D, et al. (2012) How to achieve a balanced and delicate lower third of the face in orientals by mandibular contouring. Journal of Plastic, Reconstructive \& Aesthetic Surgery 66: 47-56.

5. Chang EW, Lam SM, Karen M, Donlevy JL (2001) Sliding genioplasty for correction of chin abnormalities. Arch Facial Plast Surgery 3: 8-15.
6. Rosen HM (1995) Aesthetic guidelines in genioplasty: The role of facial disproportions. Plast Reconstr Surg 95: 463469.

7. Miloro M, Kolokythas A (2012) Management of complication in oral an maxillofacial surgery.

8. Morera E, Scola E, Mir N, Moran AM (2008) Tratamiento de las deformidades del mentón. Acta Otorrinilaringol 59: 349-358.

9. Frodel LJ (2005) Evaluation and treatment of deformities of the chin. Facial Plastic Surgery Clinics of North America 13: $73-84$.

10. Zamora C (2004) Compendio de Cefalometría. Análisis clínico y práctico Caracas. Amolca.

11. Holdaway RA (1983) A soft-tissue cephalometric analysis and its use in orthodontic treatment planning. Part I. American Journal of Orthodontics 84: 1-28.

12. Legan H, Bustone C (1980) Soft tissue cephalometric analysis for ortognathic surgery. Journal Oral Surgery 38: 744-751. 